を加えないでそのほかは前記と同様に操作したものを用 いる.

\section{4 本法による定量結果}

Tab. 2 は水銀法食隍電解工場に抢ける数種の試料中 のマグネシウムを定量した結果である.

試料採取量は $20 〜 25 \mathrm{ml}$ が好適であった. 試料の量が 多くなると含まれている不純物も多くなりかえってマグ ネシウムの誤差が大きくなった. 本法の所要時間は約 60

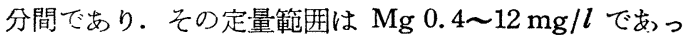
た.

\section{文献}

1) I. M. Kolthoff : Biochem. Z., 128, 344(1922). F.J. Welcher: “Organic analytical Reagents", Vol. 4, 391 (1948).

2) E. B. Sandell : "Colorimetric Determination of Traces of Metals”, 422 (1950).

3) A. E. Willson, I. W. Wander : Anal. Chem., 22, 195 (1950).

(昭和 31 年 12 月 26 日受理)

クロム酸イオンを指示薬よする硝 酸鉛標準溶液によるエチレンジア ミン四酢酸の濁度なよび湇度滴定

武者宗一郎・宗 森 信・小川欣也*

\section{1 緒喜}

クロム酸イオンを濁度指示薬として用い, EDTAを 硝酸鉛標準溶液で滴定する方法を研究した．この方法は 当量点において生成するク口ム酸鉛の沈殿を終点検知手 段とする方法であるため，肉眼による滴定は困難である。 光度滴定装置を利用し, 濁度および朧度滴定を行えば, 満足な結果を得る。このように濁度指示薬を用いる ED TA の不均一系光度滴定法は今日まて研究されていな $(1)$.

\section{2 試薬拒よび装置}

硝酸鉛標準溶液 : 市販特級品を精种し, 蒸留水に溶解

* 大阪府立大学工学部
して調整した（10.16 および $\left.11.68_{8} \mathrm{~m} M\right)$ 。

EDTA 標準溶㳞: 市販品 $\left(\mathrm{Na}_{2} \mathrm{H}_{2} \mathrm{Y} \cdot 2 \mathrm{H}_{2} \mathrm{O}\right)$ を蒸留水 にとかして調整し，その濃度を硫酸銅標準溶液でムレキ サイドを指示薬とし, 光度滴定法によって決定した2)

(17. 56, $\mathrm{m} M)$.

$5 \%$ \%ムム酸カリウム溶液.

$0.2 M$ 酶酸一酢酸ナ・トリウム緩衝溶液（ $\mathrm{pH} 4.52 ）$. 柳本光度滴定装置 PT -1 型 3 .

\section{3 実験扔よび結果}

一定量の EDTA 溶液を滴定槽に採取し，5\%クロム 酸カリウム溶液 $2 \mathrm{~m}$, 緩衝容液 $40 \mathrm{ml}$ を加えたのち, 蒸 留水で全容を $50 \mathrm{~m}$ 几し, 酳酸鉛溶液で滴定する. 濁度 滴定の際はクロム酸1オンり減少にすとづく吸光度変化 の影響をさけるため $610 \mathrm{~m} \mu$ の干渉フィルターを用い, 一定量滴下するたびに As 目盛を**，また朧度滴定の場

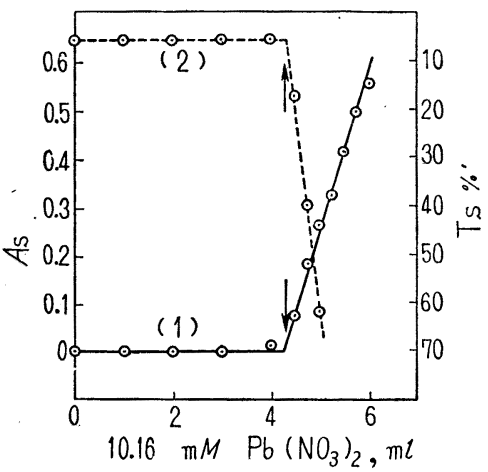

Fig. 1 Examples for (1) turbidimetric and (2) nepherometric titration curve

Tab. 1 Results of turbidimetric titration of EDTA with $\mathrm{Pb}\left(\mathrm{NO}_{3}\right)_{2}$ using $\mathrm{K}_{2} \mathrm{CrO}_{4}$ as an indicator

\begin{tabular}{|c|c|c|c|}
\hline \multirow{2}{*}{$\begin{array}{c}17.56_{9} \mathrm{~m} M \\
\text { EDTA } \\
\text { Taken, } \mathrm{m} l\end{array}$} & \multicolumn{2}{|c|}{$\begin{array}{c}\mathrm{m} l \text { of titer } \\
10.16 \mathrm{mM} \mathrm{Pb}\left(\mathrm{NO}_{3}\right)_{2}\end{array}$} & \multirow{2}{*}{$\begin{array}{c}\text { Error } \\
\%\end{array}$} \\
\hline & Theoretical & Experimental & \\
\hline 2.51 & $4.33_{9}$ & $4.32_{0}$ & -0.46 \\
\hline " & $" \prime$ & $4.32_{0}$ & -0.46 \\
\hline " & " & $4.34_{0}$ & +0 \\
\hline " & $" \prime$ & $4.34_{0}$ & +0 \\
\hline 4.98 & $8.68_{5}$ & $8.66_{3}$ & -0.59 \\
\hline " & " & $8.69_{8}$ & +0.35 \\
\hline " & " & $8.67_{3}$ & -0.34 \\
\hline " & "I & $8.7 C_{3}$ & +0.60 \\
\hline
\end{tabular}

** 吸光度は沈殿の生成量に比例し, 沈殿の生成量は潼 定量に比例すると考えら水る。 
Tab. 2 Results of nepherometric titration of EDTA with $\mathrm{Pb}\left(\mathrm{NO}_{3}\right)_{2}$ using $\mathrm{K}_{2} \mathrm{CrO}_{4}$ as an indicator

\begin{tabular}{|c|c|c|c|}
\hline \multirow{2}{*}{$\begin{array}{c}17.56_{9} \mathrm{~m} M \\
\text { EDTA } \\
\text { taken, } \mathrm{m} \iota\end{array}$} & \multicolumn{2}{|c|}{$\begin{array}{c}\mathrm{ml} \text { of titer } \\
10.16 \mathrm{~m} M \mathrm{~Pb}\left(\mathrm{NO}_{3}\right)_{2}\end{array}$} & \multirow{2}{*}{$\begin{array}{c}\text { Error } \\
\%\end{array}$} \\
\hline & Theoretical & Experimental & \\
\hline 2.51 & 4. $33_{9}$ & $4.37_{0}$ & +0.68 \\
\hline "I & $" \prime$ & 4. $34_{1}$ & +0.01 \\
\hline " & " & $4.32_{5}$ & -0.35 \\
\hline 4.98 & $7.4 \varepsilon_{7} \dagger$ & 7. $46_{8} \dagger$ & -0.75 \\
\hline
\end{tabular}

$+11.68_{8} \mathrm{~m} M \mathrm{~Pb}\left(\mathrm{NO}_{3}\right)_{2}$

合は散乱光のみであるからフィルターを用いず，Ts\% 目盛をよみとり*，これらの值を滴定量に対してプロッ トして滴定曲線を作成する.このようにして得た滴定曲 線をFig. 1 に示し, Tab. 1 および Tab. 2 に結果を総括 した. Fig.1 からわたるように保護コロイドを加えなく とも実測值はよく直線にのり二本の直線の交点は矢印で 示した当量点とよく一致している. Tab. 1 および Tab. 2 に示したよ5に誤差士 $1 \%$ 以下で滴定が可能である.

本法はク口ム酸鉛の沈殿生成による終点指示法である から従来の金属指示薬を用いる逆滴定法より妨害物が少 なく，工業用水中の EDTA の定量に適する尚のと考光 られる.

(昭和 32 年 6 月 24 日, 日本化学会東北支部常会講演)

\section{文献}

1）上野景平：“キレート滴定法”，225（1956),（南 汇堂).

2) A. Ringbom, E. Vänninen : Anal. Chim. Acta, 11, 153 (1954).

3）武者宗一郎: “分析化学講座”, 5-B, 59 (1956), (共立出版).

(昭和 32 年 7 月 6 日受理)

\footnotetext{
* absorptancy, 1一Ts, は沈殿の生成量飞比例すると 考えられるので，滴定溶液の添加量に対して Ts \% をプロットすればよい。
}

\section{粉末鉄触媒中の酸化鉄の定量法}

\author{
村田 義夫・笠阊 成光 ${ }^{* *}$
}

各種含鉄試料中の酸化第一鉄の定量法としては田沢の 詳細な研究11があり，昇录法によって金属鉄を分離した 残渣を沃度アルコール溶液で処理して遊㒕水銀を溶解分 離したのち酸に溶解して定量する方法 (昇永-沃度法)が 推将されている. もちろん反応性の異なる各種の試料に ついて金属鉄を正確に分離定量することが大切である. 著者らはさきに反応性の大きい微粉末鉄触媒中の金属鉄 の定量法について検討し, 昇求の適量を使用する試謬法 が適当であることを報告しだ2. そこで同様な試料につ いて酸化第一鉄扣よび酸化第二鉄を正確に定量する方法 を明確にするために，尘として昇承一沃度法について検 討し, 従来の操作の一部を改変することにより一回の种 取試料で比較的簡监迅速に分析できほぼ满足すべき結果 が得られることを確認したので，その概要を報告する。

\section{1 試料打よび分析操作法}

使用した各種試料（還元鉄，酸化第一鉄，四三酸化鉄 酸化第二鉄およびこれらの混合物）は既報22 のものと同 様である.

陚料 $300 \mathrm{mg}$ を科取し，既報の方法によって $4.3 \%$ 昇 永水溶液（昇秀使用量は金属鉄量の約 10 倍）で処理し て金属鉄を分離定量し，口紙上の残渣をアルニールで洗 浄して水分を除去する.

つぎにこの残渣をロ紙とともに三角フラスコに移し， $4 \%$ の沃度アルコール溶液を 30〜 $50 \mathrm{cc}$ (遊離水銀を溶 解するに必要な量) 加光, 逆流冷却器をつけて緩やかな 浙滕状態を保ちながら時々ふりまぜ，20〜30 min 処理 して冷却後口過する. 残椬は無水アルコールで洗浄して 沃度を完全に除いたのち蒸留水で洗浄してアルコール を除き，口紙とともに三角フラスコに移して希硫酸、1 9〜12) 100〜 $130 \mathrm{cc}$ を加立逆流冷却器をつけて炭酸ガス の気流中で 20 30 min 煮沸処理し，急冷後口過して残 渣を洗浄する．口液（100〜200 cc) に 2 モル濃度の燐酸 溶液 1C〜15 cc を加え第二鉄イオンを無色の錯塩とし, ただちに 1/10〜 $1 / 50 \mathrm{~N} \mathrm{KMrO}_{4}$ で滴定して $\mathrm{FeO}$ を定 量する. つぎに滴定後の液にアルミニウムの薄片 0.4 